artes da vida 


\section{Fotos de LUIZ DE CASTRO FARIA}
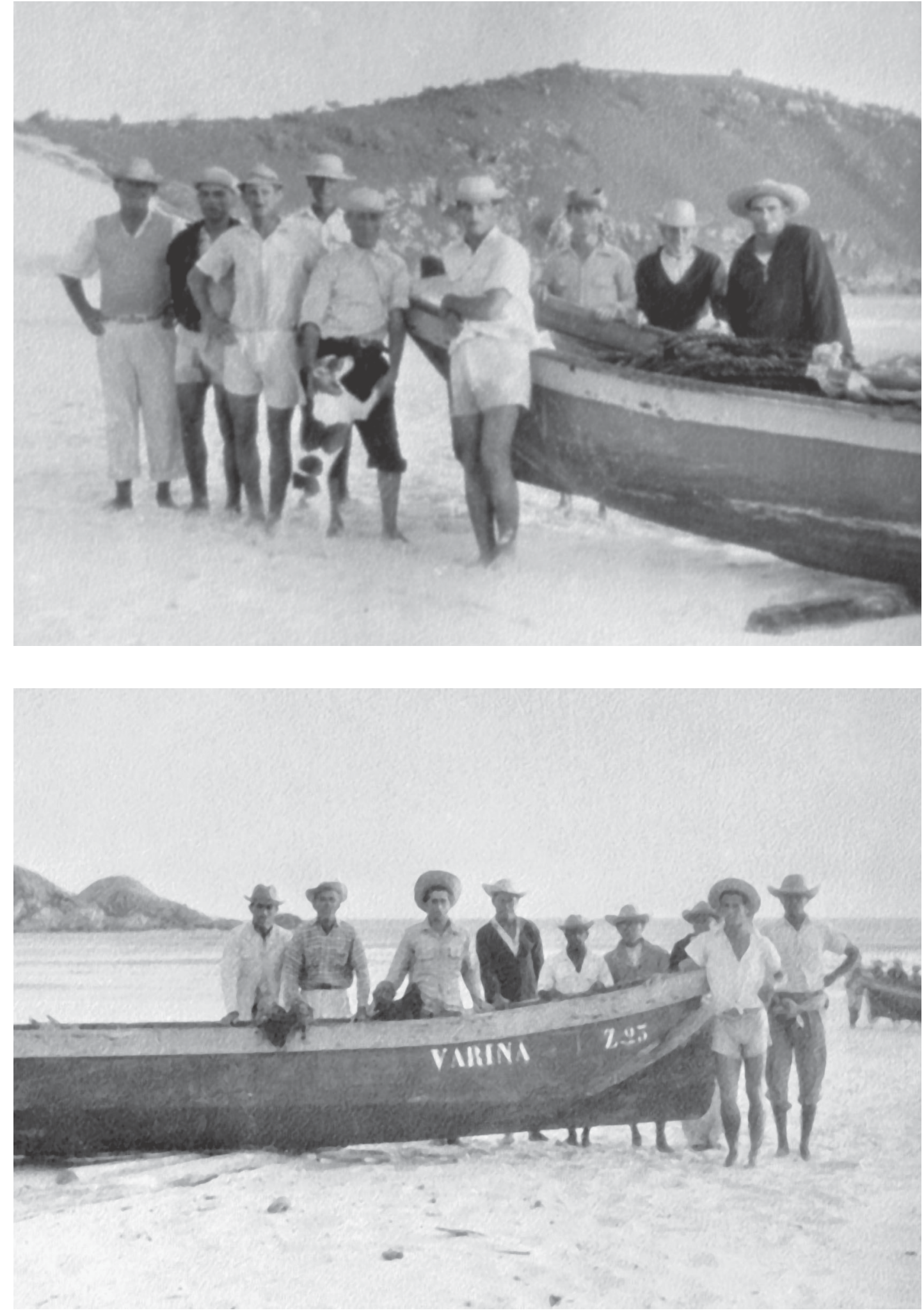

cadernos de campo $\cdot$ n. $10 \cdot 2002$ 

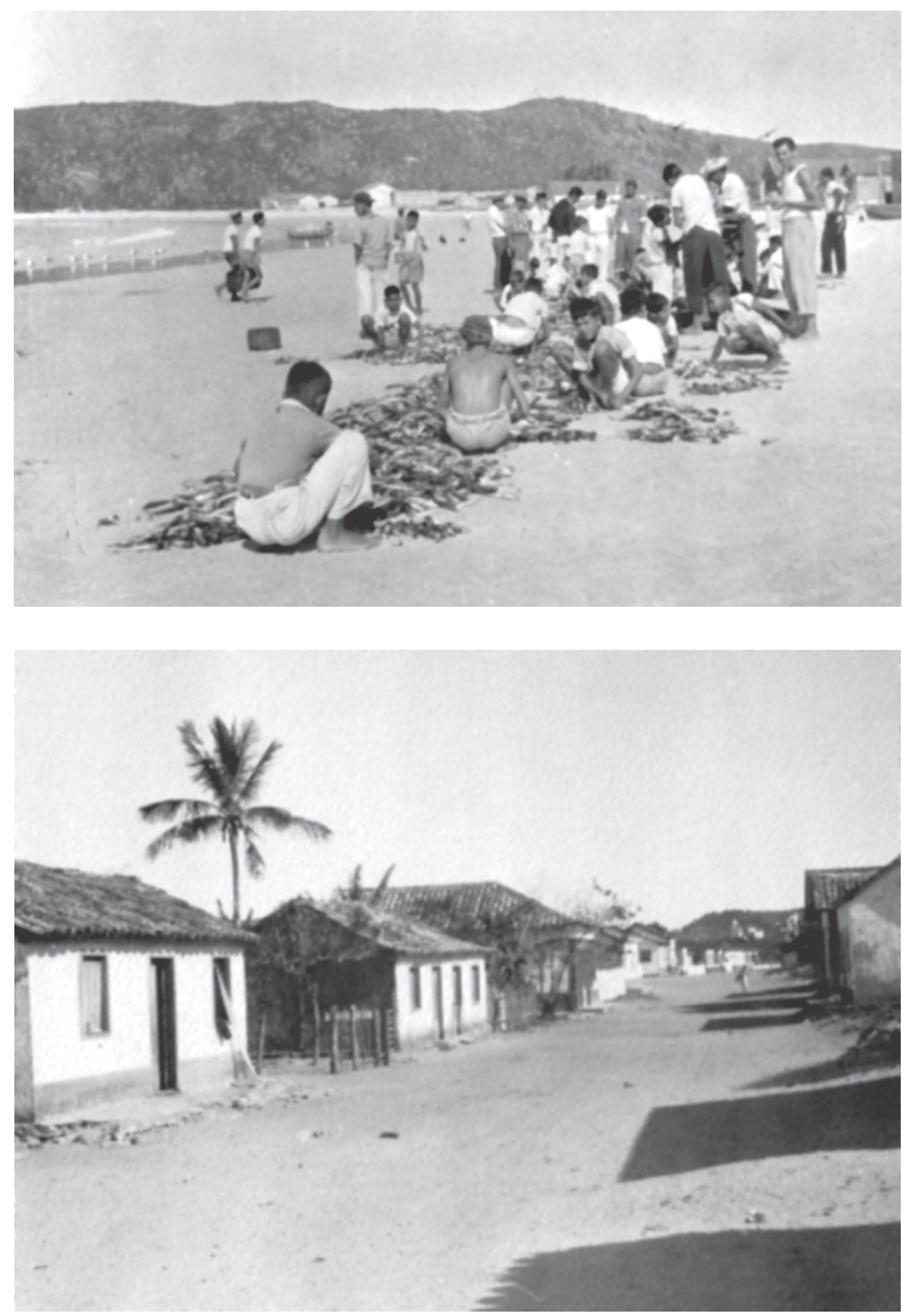

artes da vida 


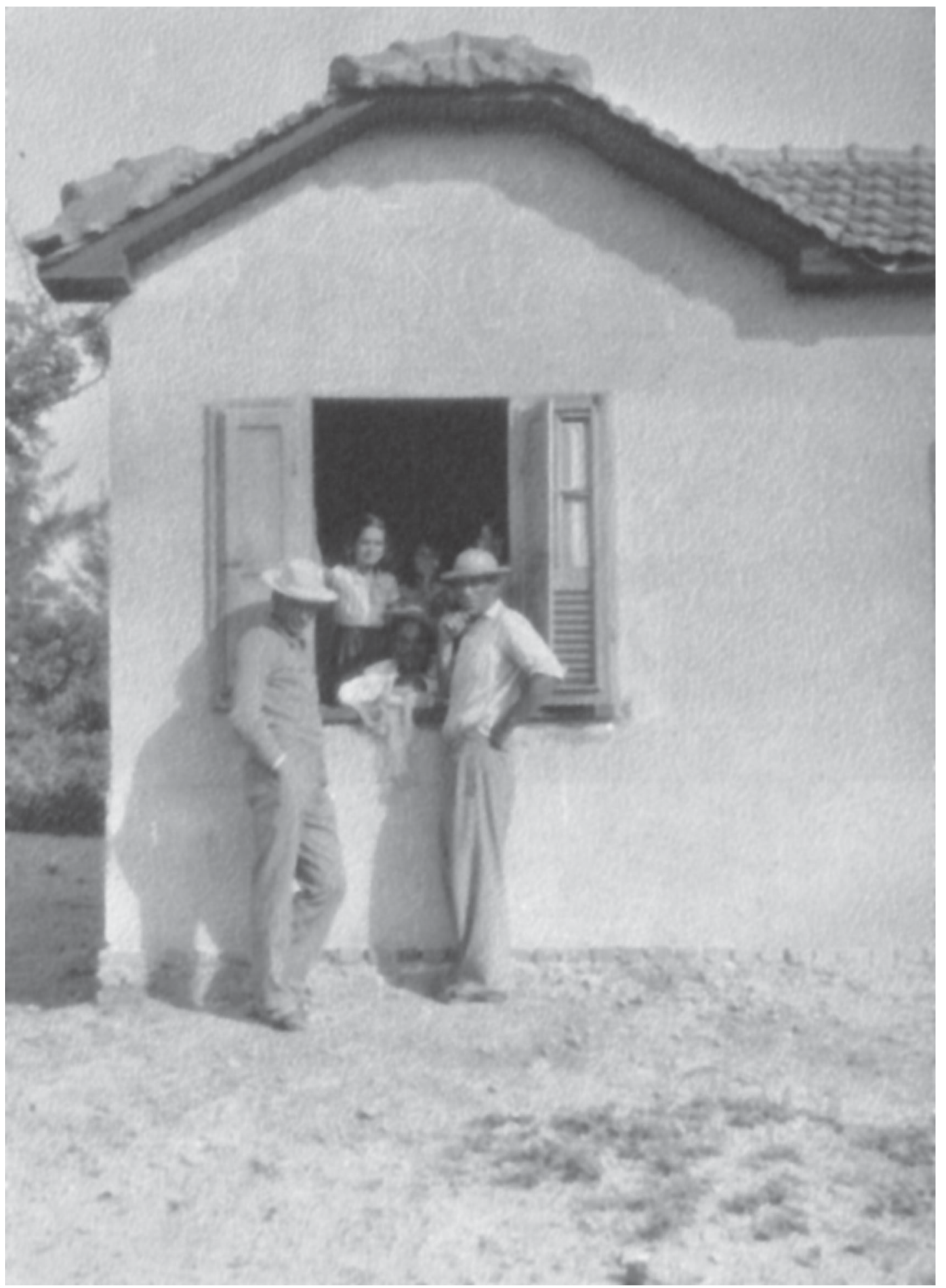

cadernos de campo $\cdot$ n. $10 \cdot 2002$ 